\title{
IJTARP
}

\section{Discount of Person, Meaning, and Motive}

\section{(C) 2019 Stephen B Karpman, MD}

\begin{abstract}
There are three types of Social Level discounting that can interfere with bonding and intimacy during relationship building - the Discount of Person, Meaning, and Motive. These can be a block in any friendship, family, romantic or business partnerships. They discount in others the OK potential of who they are, of what they say, and why they say it - and what they could be. The same discounts of personal worth, potential and hope will also apply internally in the transactional relationship with oneself at the psychological level.
\end{abstract}

\section{Discount of Person}

"What can we know, what can we see, when error chokes the windows of your mind." Sir John Davies (Grossart, 2012).

"Know yourself, presume not God to scan, the proper study of mankind is man." Alexander Pope (Applebaum, 1994).

This is a paper written in the style of Eric Berne's Social Level TA; in other words, it is all about observations of what people do with each other and why. As Pope recommends above, this paper is about "the proper study of mankind" with his other focus on "know yourself" What Davies recommends above, concern is with "when error chokes the windows of your mind." We deal here with errors in knowing people when they discount each other as human beings.

Prior discounting theory in transactional analysis has been on psychological level TA, models developed at the Cathexis Institute; the passive behaviours in problem-solving that discount stimulus, problem, significance, solvability, and self or others capacity to solve the problem. (Schiff and Schiff, 1971) (Mellor and Schiff, 1975a, 1975b).

The focus here is on four observations of people, and combinations thereof, of what you like in them in the way of their (Head) thinking, (Heart) feeling, Gender and Work qualities, those qualities charted in the
Discount of Person Matrix (Figure 1). The paper later deals with the communication process that interferes with relationship solving by the discounting of the OK meaning of what someone says and discounting the OK motives of why they are saying it.

Transactional analysis was created by Eric Berne to introduce the hard-medical systems he learned as a physician into the soft psychological systems prevalent in the psychoanalytically oriented psychology of the day. The medical rules he followed required real-time observation, measurement and proof, all well thought out to their reductionistic end point using Occam's Razor Law of Parsimony - the scientific standard in the wider world of science for five centuries. The scientific diagrams of the medical profession Berne introduced to TA were diagrams, lists, charts, graphs, and formulae, and written up in easy to read layperson's language.

His circle of trainees in his 1960s 202 seminars followed all his rules and examples which included the egogram (Dusay, 1972) that placed intuitive observations of ego states into five-part graphs, and the drama triangle (Karpman, 1968) that created a three-cornered diagram for illustrating the three roles played during games. The Discount of Person of this paper is a four-part matrix offering a place to organise four common social readings of the most OK desirable qualities in people.

The classic Leonardo da Vinci circular drawing of a man is expanded in Figure 1 into sections to graphically represent a person's mind, heart, gender, and work, with a negative $X$ mark representing the discounting of those qualities from dislike all the way down to disgust, and a positive $\sqrt{ }$ mark acknowledging and treating the other person with from liking all the way up to awe. Reading across the four horizontal rows are the four qualities:

HEAD $\sqrt{ }$ or $X$. (for thinking - intelligence and problem solving). Discount of Brain.

In these horizontal rows, the check mark $\sqrt{ }$ represents the automatic positive assumption that there will be 


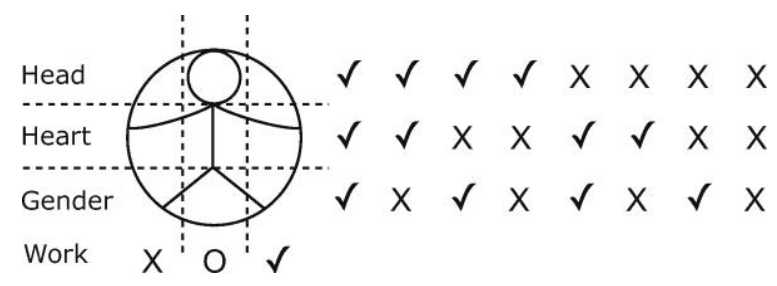

Figure 1: The Discount of Person Matrix.

intelligence, thinking and useful information and discussions from the person you are talking to. The $X$ mark indicates the negative assumption that these are missing and the person is incomplete. These $\sqrt{s}$ and Xs can also apply to one's evaluations of oneself and the world.

HEART $\sqrt{ }$ or X. (for feelings - kindness and warmth), Discount of Heart.

The check marks $\sqrt{ }$ represent the automatic positive assumption of passion, sensitivity, caring, praise, reassurance and forgiveness in your experience with the person you are talking to. The $\mathrm{X}$ mark indicates the negative assumption that these are missing and the person is incomplete. These $\sqrt{ } \mathrm{s}$ and $\mathrm{Xs}$ can also apply to one's evaluations of oneself and the world.

GENDER $\sqrt{ }$ or $\mathrm{X}$ (for sexuality - gender, attractiveness), Discount of Sex and Gender.

The check marks $\sqrt{ }$ represent the positive assumption of the welcome and beneficial differences of gender in others including the best of masculinity and femininity, and gives the other person the benefit of doubt by relating to them socially as they expect. The $X$ mark indicates the negative assumption that these are missing and the person is incomplete. These $\sqrt{s}$ and Xs can also apply to one's evaluations of oneself and the world.

\section{WORK $\sqrt{ }$ or $X$ (for work - skill and willingness to} work). Discount of work.

In the vertical side columns, the arms and legs represent work. A $\sqrt{ }$ mark represents the willingness to work productively without reminders and delays, and working at high standards with clear contracts and agreements, and to complete the work on time including clean-up and a call-back. It includes offering detailed praise for the work - but also accepting as OK what someone honestly can and cannot do. The $X$ mark may also be a hired worker or a spouse refusing to do the expected work around the house, or go out and get $a$ job. These $\sqrt{ }$ s and Xs can also apply to one's evaluations of oneself and the world.

\section{WORK 0}

The centre column is of a full 'non-person' at work and read as a Zero (0). The person is seen as a blank and invisible. It is called a 'furniture' reading, no reaction to them. The 0 will go unnoticed and not receive favours or praise for their work that others may receive. A 0 also could be a reading on a stranger on the street who you have no reaction to and they have no reaction to you. If there is building up of a dislike of the person at work all the way up to their entire existence being hated, replace the 0 with an $X$ ! If there is admiration and respect for the full worker as a human being who is universally welcomed as a teammate, they are marked with a full body $\sqrt{ }$ ! These $0 \mathrm{~s}, \sqrt{\mathrm{s}}$ and Xs can also apply to one's evaluations of oneself and the world.

\section{One-Dimensional Stereotypes}

Looking now at some complex readings in Figure 1, the diagram can be used to expose common onedimensional stereotypes reading as just a single $\sqrt{ }$ and the rest Xs.

$(X X \sqrt{ })=$ all men want is sex

$(X \vee X)=$ all women want is love

$(\sqrt{ } X X)=$ all nerds want are computers,

We can add in the Work factor

$(X X X \sqrt{ })=$ all big guys are only good for helping me move to a new apartment.

$(\sqrt{ } \sqrt{ } X)=$ all women are wonderful but they make too many mistakes so who needs them?

\section{The Full House Stereotype}

This is four-level stereotyping with either all Xs or all $\sqrt{ }$ s. Contrast the readings by a Pessimist, and an Optimist:

\begin{tabular}{|c|c|}
\hline Pessimist & Optimist \\
\hline X all people are stupid & $\sqrt{ }$ all people are brilliant \\
\hline X all people don't care & $\sqrt{ }$ all people are loving \\
\hline X all people are unattractive & $\sqrt{ }$ all people are beautiful \\
\hline X all people are lazy & $\sqrt{ }$ all people are helpful \\
\hline
\end{tabular}

The Discount Combinations.

There are many possible combinations. A stereotype of $X \sqrt{ } \sqrt{ }$ could be applied to a hard worker with the mindlessness script (Steiner, 1966). The opposite stereotype of $\sqrt{ } \sqrt{ } X$ could be applied to a lazy loving person dismissed as a flake by being too changeable and terminally unreliable.

Some people do not escape their stereotype, or they contribute to it, or they trap others to contribute to it by the needs of their script. If someone has a grudge they will not let go of the stereotype of the other. The eight total possible combinations were reflected in the original name of the diagram of Double Discounting Octanopia - eight (Octa-) ways of being blind (-nopia) to the potential in others including work and self. 
Some Common Dating Stereotypes.

Examples from singles' dating scene, where snap judgments may quickly end relationships that could have been promising if the people put in the work, include from a singles' group:

$\sqrt{ } \sqrt{ }=$ He saw his blind date as intelligent (head $\sqrt{ }$ ), warm (heart $\sqrt{ }$ ) and sexy (gender $\sqrt{ }$ ). He is happy. It was love at first sight and he gave her unconditional positive regard. But love is blind, was he too optimistic? He never thought that changes could occur in that perfect relationship. Did that come later?

$\sqrt{ } \mathrm{X}=$ She saw that same blind date guy as knowledgeable $(\sqrt{ })$ lovable and funny $(\sqrt{ })$ - and too romantic! - and she assumed he would be too pushy sexually. From her past experiences she could not handle men who were like him and she will not go out with him again. Her non-winner script called for her to settle for less and avoid the memories of the childhood sex abuse she discussed later in therapy.

$\sqrt{ } X \sqrt{ }=$ Another woman on a blind date could only be physically attracted to intelligent unattainable men of distance who could express no feelings (heart $\mathrm{X}$ ). This one was more attracted to his computer, the apple of his eye. This was a familiar challenge to her because she could never please her self-absorbed father. In her Sisyphus Over and Over script, she hoped that if she would just Try Hard to Please Him for a year or two, the boyfriend would eventually warm up some day and give up his 'career nerd' script of living in his family basement. Well, he never did warm up, so after a year of Try Hard she moved on to another Try Hard project, always with intelligent men who were her projects needing Rescue with their feelings.

$\sqrt{ } \mathrm{X} X=\mathrm{He}$ complained to her "You only love me for my mind and not my body." She wanted him for that dreaded male F word = Friend. She was a Snow White finding her Seven Dwarves. He felt used and did not want that neuter deal. He recalled a Rodney Dangerfield complaint on stage, "My mother wouldn't breast feed me. She said she only loved me as a friend."

$X \sqrt{ }=$ No, he didn't seem very smart (head $X$ ) but was the sexy hunk (gender $\sqrt{ }$ ) she always wished for and he was very kind to her (heart $\sqrt{ }$ ). She was the brains of the relationship and the very successful breadwinner in the family, so he rarely worked. When she wanted him to get a job he could always out-talk her with clever excuses. Maybe he was smarter than she thought he was.

$X V X=H e$ was never attracted to her physically (gender $X$ ). She was such a warm loving woman (heart $\sqrt{ })$ she felt she had no need to risk exposing her intelligence (head X). But she had a big heart and that felt good and somehow they got along. Her role in her alcoholic family growing up was to play the classic Mascot and Hero role and the Rescuing peacemaker. That suited him fine. She was a very loving woman to him but could not understand why there was no sex in the relationship. At work she always made the coffee and loved helping people.

$X X \sqrt{ }=$ She complained "You only love me for my body and not my mind." but he quipped "If you had a mind, I would love that too?' She smacked him. But she hid her mind from men. She overplayed the sexy teaser stereotype and overemphasised her looks because the easy strokes were there and she would feel insecure without that. She complained that people did not take her seriously at work; they labelled her as cute. Men saw her as a one-night stand, found themselves bored in the morning, and did not call back. She did not figure out why (Head X).

$X X X=$ He was a sullen date who discounted all the people in the world as being defective losers. He discounted their redeeming qualities. So much unhappiness was unnerving to his blind date and she declined further dates. He saw others through the stereotype of $X X X X$. He put them down. They were not worth getting to know. Why? His absentee alcoholic parents continually neglected him. In his defence, he had eventually made a stay-away Don't Be Close script decision as a child.

He was able to work for just a year (add a temporary $\sqrt{ }$ for work) but he was too negative, creating dissension and division at work and the boss had to fire him. He became homeless. He stopped working (a X for work now). He slipped into an I'm Not OK, You're Not OK, They're Not OK position; a full house XXXX just the way his parents treated him, and the script went full circle.

\section{Work Stereotypes}

Let's take a closer look at the Work row beneath the figure. If someone works they get an added $V$, not working gets them an added $\mathrm{X}$. Some examples of each:

$\sqrt{ } \sqrt{ } \sqrt{ }=$ the hardworking OK person. The teenagers did their chores and were praised and rewarded generously.

$\sqrt{ } \sqrt{ } \mathrm{X}=$ the non-working OK person. She loves her husband but cannot get him to go out and find work. To remain in love, and for the children, and for the house, she believed his excuses.

$X X X V=$ the hardworking non-person. This distant manager expects hard work but never gives praise because of assumptions the staff will goof-off and steal the pencils.

$X X X X=$ the non-working non-person. The homeless person seeks attention but is ignored. 
Top Ten Uses of the Discount of Person Matrix This matrix is used for knowing what combinations you are projecting onto others and what they are projecting onto you, accurately or inaccurately, spoken or unspoken; these perceptions affect the hopes and disappointments in the communications process during relationship building. Some uses are:

\section{As a Discount Matrix}

Use the readings to accept, compromise, tolerate, avoid, change, overlook, bypass, sympathise, or move on. Discuss it with the person to lessen the importance of the Xs and to appreciate better the $\sqrt{ } \mathrm{s}$ that balance everything off, and hear what they have to say about you.

\section{As A Reality Testing Matrix}

Know to whom you are talking and the you to whom they are talking. In TA, know the egogram of the person you are talking to and their PCM personality type (Kahler, 2008) and drivers (Kahler, 1975) - for example, are they a Thinker with a Be Perfect driver, or a Dreamer with a Be Strong driver? And know who they are talking to.

Use the matrix in a group workshop exercise to test your readings against others' readings. Get positive support when your intuitions match those of the majority. Some people do not believe they have intuition until they check it out with others. Others act on false intuitions without being aware it is happening and this affects their choices.

\section{As a Hope Matrix}

Know what your ideal is in other people and in yourself. Is it realistic? In romance are you at 7 expecting to score a 9.5. Which characteristics are the most important - or are all four equally important? Have you set up a plan to find the ideal person and for you to become the ideal person for them? Those can be contracts in therapy. Are your communication skills for conflict resolution based on hope or do you need to become better at it to get what you want in home and business life?

Snow White sang Someday My Prince Will Come assuming he will be a $\sqrt{ } \sqrt{ } \sqrt{ }$ - and of course he was. This can be your fairy tale dream of what you wish others will be able to give you as perfect partners, friends, and co-workers, or what your idealised family could be someday. Do you need to brush up on your social skills of head $(\sqrt{ })$ and heart $(\sqrt{ })$ to get what you want? It would be more difficult if you are fighting a Don't Want script decision. The power of dreams can drive the triple steps necessary to change your life in 'Make Your Wildest Dream Come True' (Karpman, 1985, 2019).

\section{As a Self-Awareness Matrix}

Know that the four readings that you are making on others, they are also making on you. Can you accept those readings by others and adjust for them? Do you have the good in you and the bad in you well memorised and balanced knowingly on the Adult Scales (Karpman, 2012) to ward off defensiveness when new criticism surprises you during communications?

There are many TA tools for self-monitoring such as knowing which ego state is talking, knowing which ego state is showing, knowing which discount is starting a game, knowing which driver is reinforcing the game, and knowing which script decisions are directing the game? Sometimes people send out heavy second-and third-degree signals of the game of Kick Me.

What is your responsibility in accepting the feedback of others? What do you do with the readings you receive? You can accept the feedback, or at least some of it, using the $10 \%$ solution $-10 \%$ of anything a person says to you is true and $10 \%$ of the world population would agree with them. And 10\% of anything a person says to you is false and $10 \%$ of the world population would agree with them (Karpman, 2014).

\section{As a Kick Me Matrix}

Are you unknowingly sending out self-defeating signals for a transactional game of Kick Me or You'll Have To Take Me As I Am? What projections are you attracting from other people? How do you do it? If it is happening, what is your magnet? If it turns out that you have hung a Kick Me sign on yourself, get rid of that sign.

Do your drivers attract unwanted transferences, or paranoia, or worse, absorb bad Karma from another's dark past? What reasons why do you assume, as opposed to what actually happens? What does your feedback tell you? The answer should come out clear in group therapy and with a contract in individual therapy. The world takes you at face value. It is not who you are that people see but what you show to others.

\section{As a Stroking, Pride, Appreciation and Benefits Matrix}

As a Stroking Matrix, which of the four qualities do you stroke most often in others? How do you encourage them to be the best they can be? What do you not stroke and not recognise daily in others? Do you notice what people want stroked that you might have previously been discounting?

\section{As a Pride Matrix:}

- Ask "Are you proud of these four qualities in your partner and do you stroke them enough?"

- Ask "Are you proud of these four qualities in yourself and stroke yourself enough?

- Ask "Is your partner proud of your four qualities and strokes them enough?" 
As an Appreciation Matrix. For which of your qualities do you want strokes? Do you savour and fully incorporate the good ones that people spontaneously give you so that you feel better about yourself? Do you show appreciation when you receive those strokes; if so, they will be more likely to give more of those in the future.

As a Benefits Matrix. Count your blessings. Do you know the advantages and possibilities and benefits you receive from the other person - and tell them that? What can you develop more fully in yourself so that you can offer more benefits to others who know you? Getting yourself well-rounded will give more benefits to your partner and others to increase your welcome in more arenas.

\section{As a Partner Matrix}

At home, look at your partner sleeping or reading a book in a chair - what do you see? When your partner glances at you, what do they see? The chart can be used in a couple's exercise in a safe setting where each person does their reading of the other and the reading of themselves. Then they practice a more sensitive way of sharing, and get better at it each time, where discussions of new and old issues, and even trading stamps (Berne, 1964a), can be cleared up, and both can end up positively with relief, with thanks, smiles and a hug.

The sharing is better when the Five Trust Contracts for Couples (Karpman, 2014) are in place between the paired OK ego states:

- Between the CP+s, The No Collapse Contract,

- Between the NP+s, The Protection Contract,

- between the A+s, The Openness Contract,

- Between the $\mathrm{FC}+\mathrm{s}$, The Enjoyment Contract,

- Between the AC+s, The Flexibility Contract.

\section{As a Liability Matrix}

Have you as a Rescuer done a Liability Matrix on your partner, or on yourself as a partner? Are you Rescuing a partner or friend who is endlessly playing the Victim role in a situation that has permanently gone bad but you do not have the clarity to justify a long-overdue quit that may be best for both people? You hold out hope, perhaps there is a chance to work it out. Use it as a Choice Matrix to decide who you do and do not want in your life, and if they really do or do not want you. Discuss first the readings for trading stamps that can be cleared up with honest communication, and if there are known script reasons behind it.

Have you done a Liability Matrix on your place of employment where you are not happy but do not think you should be quitting? Is there a dysfunctional game going but you do not know how to escape? (Karpman, 2014).

\section{As a Psychotherapy Matrix}

A scan of the chart and the discussions that follow can set up a workable contract for therapy. These could include decontaminating the Adult of delusions and prejudices, classic social level game analysis with the half dozen or so advantages for the games explored, redeciding underlying script decisions, the discounting of problems and solvability with passive behaviours, and deep cathartic work with resolution of transferences, among many others.

\section{As a Workshop Matrix}

In an educational session the diagram immediately conveys the impression that individuals have depths, and their needs are varied. It shows how easy it is to misread others, and how people-reading can be improved with TA training. Private, organisational, scholastic, or rehabilitation workshops present an educational opportunity for didactic learning combined with designed practice sessions with group intuition exercises where participants can sharpen their intuition skills by checking out their feedback with others.

In the theory sessions one goal would be to learn the difference between Adapted Child intuition (false readings to advance the script), as opposed to Free/Natural Child tuition (game free readings are more accurate from the Natural Child).

People can learn about the limits of Child intuition from two intuition games; the I've Got Perfect Intuition game corrupting the Adult with grandiosity (Free Child contamination), or the I Can't Ever Trust My Intuition game (Adapted Child contamination).

Free Child intuitions can be inadvertently blocked by each ego State:

- CP- Cultural stereotypes and hard-nosed scepticism;

- NP- Rescuing others with what they want to hear;

- A- Left brain information blocks the right brain intuition

- $\mathrm{FC}+$ Natural Intuition (intuition is different from ESP (extra sensory perception) knowing);

- AC- Paranoia. projections, transferences and suspicion.

Adult contaminations which are believed to be Adult fact are illustrated in the contaminated Adult Ego State diagram in Figure 2 (Berne, 1964b). The Parentcontaminated Adult gives false prejudicial readings that are believed, and the Child-contaminated Adult has unrealistic fears, illusions or delusions, depending on a first-, second- or third-degree attachment to the idea. 


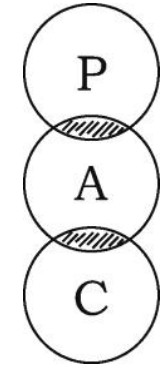

Figure 2: Ego state contaminations

How do you see yourself and how do others see you? Find out who you are - and seem to be - and what you can be. Use it to monitor yourself just as you would monitor your ego states and drivers in the company of others.

In workshop training exercises, use it to find out what signals you are sending out to others - or not sending out to others, and why. The discussion of that would include questions of what you will not allow others to fully see in you and why, and what do you overemphasise to cover that up? Know what is there and what is not there.

For a small group exercise, printed handouts of the matrix can be given out. Participants, one by one in turn, will speak for two minutes. Then each person fills it out on each other by circling the $V$ and $X$ series that seems applicable, and the group discuss it.

Use it as a teaching diagram for the four fields of transactional analysis to demonstrate that people have sides to their personalities and all those sides are important to them and need to be recognised, and how their own effectiveness can be increased by developing those sides in themselves. As a problemsolving matrix it can be used in business relationships for successful training of salespersons or planning organisational strategy and to meet the needs of clients. Similarly this would apply to counsellors and teachers for understanding their variety of students. And when you are reading them - they are reading you.

Treatment summary.

As described previously, in therapy and training the discount of person matrix is used to understand: one's discounting patterns that aid or discourage positive relationship building; how and why social discounting defends against relationship intimacy and attachment; and what to do about it. Knowledge is useful in controlling and improving stereotype awareness and improving trust in intuition by practicing correct versus incorrect intuition with group feedback in workshop exercises.

Group therapy, couples and family therapy and workshop exercises give useful feedback and a chance to discuss and practice accurate readings with others.
Intensive individual therapy can decontaminate Adult prejudices and illusions; allow redecidision of early childhood script positions; resolve transference games; and develop an understanding of how discounting advances the payoffs of games and scripts, among others.

\section{Discount of Meaning}

In the section above on Discount of Person, multiple combinations were identified of the variety of ways that people can discount the qualities and identity of who a person is, as well as the potential of who they can be.

After the discounting process is done, one may be left with the discouraging feeling that a) they cannot love that other person whom they have recently falsely discounted; or b) their true self is not loved and understood and it is too much of a hassle to clarify that; or c) they discount their own worth to the point of feeling unlovable and inadequate, and then make themselves unavailable for further closeness. Personality discounts interfere with motivation and desire to begin the problem-solving process that is needed. This next section deals with what to do about the communication of ideas and information - the Head for Thinking in the diagram.

The next step is problem solving - to fully spell out the problem and put it on the table for Adult discussion. The listening and conversational skill of each person is brought into play. Can someone ask for enough time to get across the full OK meaning of what they did and why, what they can and cannot do, what they want and do not want, who they are and are not, and how they feel about themselves and the other? Conversely do they also invite, listen and understand the meanings of what the other person has to say of who they really are and what they do?

Conversations take time. Will you be allowed to have all the time that is needed? Will you be cut off almost before you start? The Information Iceberg (Figure 3 ) is used to illustrate that there are four levels of understanding that may be needed and suggest the time that it would take to get a full resolution during relationship discussions.

From the list of the four qualities previously described - Head, Heart, Gender and Work, we will shift focus now on discount of meaning to the Head for allowing deeper communication of content - the ideas and thinking that can facilitate bonding. Later the focus will shift to discount of motive and the Heart in terms of feelings and trust during intimate communication.

Intimacy can be attained in many ways, among others in TA practice:

a. In the connecting of up to all nine channels between ego states in Berne's Relationship Diagram (Berne, 1961); or 
b. In the open and transparent sharing of every OK ego state with each other $(5+5)$ illustrated by turning the Personality Pinwheel using The Intimacy Formula (Karpman, 2010, 2014);

c. The in-depth sharing of the full range of interesting topics discussed along a 0 to 100 scale of five 20point advances in intensity from distance to intimacy in the Intimacy Scale (Karpman, 2010; 2014);

d. By removing the three blocks to sexual intimacy (SDD - Scared, Disgusted, Deprived) (Karpman, 2009, 2014).

Figures $3 a, b, c)$ illustrate that there are four layers of meanings that people want to have spoken out to feel complete and to have their points all heard during problem solving discussions that get to a level of substance and depth (Karpman, 2014). A hurried or interrupting listener will not allow a speaker to get everything said they need to say - in other words there is a discount of meaning and the speaker is left feeling incomplete, misunderstood and frustrated. Some interrupting is normal.

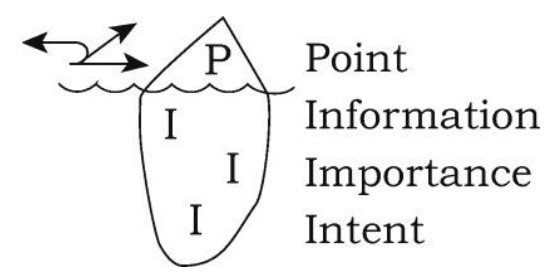

Figure 3a Information Iceberg: Discount of Meaning Personal

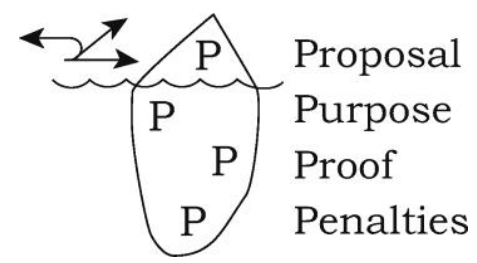

Figure 3b Information Iceberg: Discount of Meaning Work

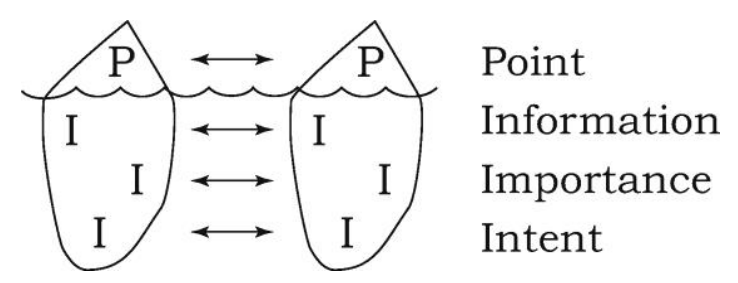

Figure 3c Information Iceberg: Discount of Meaning Partners

1. Discount of Point

At the top of the iceberg is the well thought out point that a person wants to get across. Then they want the time necessary to get all of their point heard with all the supporting information. They expect to be able to follow-up their point with all the reasons that validate their point but those further reasons are unseen to their listener as represented by the underwater line in the diagram. Some people hear only the point and do not expect any additional validating information and then switch the subject to something else as illustrated by the arrows.

\section{Make Your Point}

Some people do not know what their point is, or do not know how to think it through to a point so they just jump in at the middle of the conversation at the Information level. Without a focal point for orientation it gets confusing and the conversation may go off in random directions. Some communicators do not make their point well, others have not yet made their point interesting. In the Three Rules of Openness: Bring It Up, Talk It Up, Wrap It Up, there may need to be an earlier step of Think It Up so that a clear point is formulated in advance that will hopefully grab the attention of all three ego states in the listener: importance for the Parent, information for the Adult, and motives for the Child (Karpman, 2012, 2014).

\section{Hear the Point. Arrows.}

The three listeners arrows above the water represent three listener reactions to your point that you watch for. The direct straight arrow connects with the point, and once inside, that listener is willing to go further down into the iceberg for additional Information. Ideally he or she will repeat the point so the speaker does not have to keep repeating it.

The angular arrow in Figures $3 a$ and $3 b$ indicates that the listener skips off to a totally different, irrelevant subject, sometimes just bouncing off a single word they might have heard. The curving back arrow is the "as I was saying", self-involved, non-listener who quickly goes back to what they were talking about in the first place, and who gives no indication that a point had been made or that the person was awaiting a reply. Each of these three arrow reactions can be discussed if the listener is commonly confronted with a second point "You didn't hear my point."

The drawing in Figure $3 \mathrm{~b}$ is an iceberg variant specific to a work situation. In a crowded boardroom the employee needs to present their very well-thought-out proposal for the company with charts, statistics, and brevity; and then make it very clear what is the important purpose that would benefit the company. However, they have to have a lot of research and have proof to support that what they are suggesting is viable and new compared to what the competition is doing, plus they need to include what penalties to the future of the company will follow if their plan is not implemented. 


\section{Discount of Information}

The tip of the iceberg is someone's point and usually they still have a lot more they want to say about it and do not expect to be cut off quickly.

\section{Tell Your Information}

Indicate how much you still have to say about it. Target your information to be interesting to all three ego states in the bull's-eye transaction. Keeping it interesting, with a contract to listen, will lessen the likelihood of you being cut off or people walking out of the room. Be willing to be interrupted with questions seeking clarification, or to hear another person's parallel experiences that will enrich the conversation. Wearing a sweatshirt that says "Shut up, I'm talking" will get the listener yawning or their nostrils flaring, one of the two. A couples' diagram in Figure $3 \mathrm{c}$ shows the goal of an easy exchange of all four levels of information by both persons.

\section{Listen for Information}

If your timing and the situation are right, people who like you, or have to listen to you, or pretend they hear you, will listen and look interested and repeat your point to give you reassurance that they are with you. They can get high marks on the three intuitive listening scales where you silently grade your listener on three scales of 0 to 100: I Care, I Listen and I Change (Karpman, 2012, 2014). For example you may give your listener a reading of $80,50,0$ (they cared; sort of listened; will not change). Others, with a $0,0,0$, do not care about you the speaker, do not listen to the information, and give no indication that they would change based on anything you said. You may see on them the Bad Listener Sweatshirt: "I don't care what you say." Others discount the person (head) and exemplify the quote "Hysterics act as if the other person does not have reasons."

Ideally the attentive listener would give you your full SEVF Listeners Loop (Karpman, 2012, 2014): Strokes (maintain the relationship), Encouragement (maintains the channel of communication), Validation (maintains the credibility) and Follow-Through (maintains the purpose), which would invite future discussions and easy problem-solving in relationships.

\section{Discount of Importance}

Sometimes a person feels their point is important so they must get the other person's attention to let them know their point is important, and prove why it is important, and they will need some time and feedback on it. A caller on a radio talk show will first say "I have two points I want to make" and then they will get the time to say them; otherwise they may be cut off after a minute or two. If a person is thinking of quitting work or ending a relationship, they need to let the other person know that the discussion will be important, and the listener needs to provide quality time and quality feedback.
Delay

Sometimes a person may not have thought things through yet to realise that it is important and they may have to bring it up again at a later time when they can do a better job. Or they may be hesitant to bring it up at first for a variety of reasons.

\section{The Doomsday Topic}

Conversely, the listener may not want to deal with the point because it is too important and it might lead to conflict. Someone in the Victim role may be afraid of the subject and the Rescuer may feel they need to avoid the subject to guard the peace. Sometimes it is advisable to get an initial listening for change contract, explaining that you have something to say and you want to know if the other person is willing to talk about it then or later. Sometimes 'doomsday' subjects are too important and they always get avoided. Some couples may avoid any communication because they think it could lead to a divorce.

\section{Discount of Intent}

The bottom of the Information Iceberg can be shaped and pointed down like a drama triangle with the three roles (+ or -) of Persecutor, Rescuer and Victim filling the corners to represent concerns of why the communication is happening. A person with a PTSD (Post Traumatic Stress Disorder) family background may react defensively to everything, like a Victim fighting off a Persecutor, and not remember afterwards that anything important was discussed. The topic introduced may be an invitation to a game, hence the use of the drama triangle in the Intent area. All corners of the drama triangle can also be used in the positive manner as seen in the Compassion Triangle (Figure 4 $a, b, c)$.

In difficult situations it is necessary that the intent be clear in advance to avoid the assumption of attack. Perhaps all that will be necessary will be a few reassuring introductory sentences, such as "I love you and I know this is a sensitive subject but..." If there is goodwill it would be even better if the shared Five Trust Contracts For Couples are in place, as mentioned above.

Without communication skills or clear contracts, and if a taboo subject is too important and the intent is not clear, games could erupt to ruin the conversation. Furthermore, with too much information, archaeology of digging up the same old stamps, and possibly Blemish with everything leading up to Uproar, some latent discount of persons may emerge in that scenario and need to be cleaned out too.

\section{Discount of Motive}

We will look now at a discounter's three motives for playing a communication game or games that could be a smokescreen to conceal true feelings. However, instead of using the older drama triangle which 
exposed who are the players in the game, we will use the newer compassion triangle which exposes why the players are playing the game - the three motives for playing games that appear to replace the honest communication for which people lack skills.

Games arise from three evolutionary level survivalbased instincts illustrated by the Darwinian Triangle (Karpman, 2014) and are automatic during stress - and easier to do than learning how to communicate authentically.

For this we will use the same underwater analogy of an iceberg by drawing an inverted submerged compassion triangle (Figure 4) to illustrate that what is underneath the water is not seen or expected but may or may not bob up later in the switches in the game. The sunken triangle exposes hidden motivations during a game so they can be brought out and become talking points during problem-solving to remove discounts.

The parentheses around the roles indicate the flexibility and changeability and that the roles can be positive or negative, known or unknown, and open or closed for discussion. They can also represent cons, hooks and payoffs during a game; payoffs that could be first-, second- or third-degree and can reach titanic proportions.

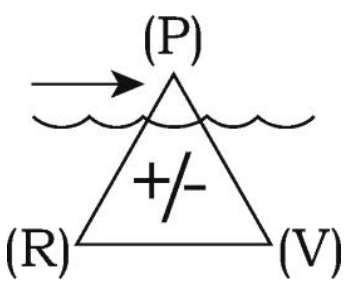

Figure 4a: The Submerged Compassion Triangle only Persecutor apparent on Top

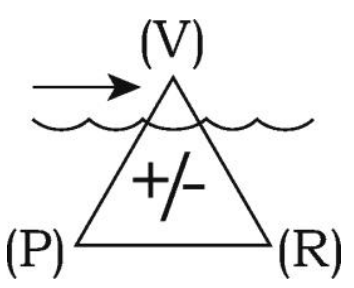

Figure 4b: The Submerged Compassion Triangle only Victim apparent on Top

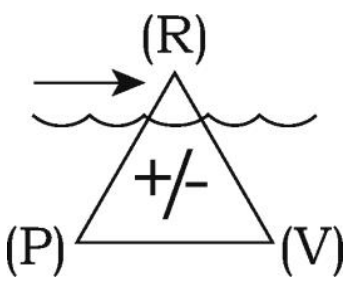

Figure 4c: The Submerged Compassion Triangle only Rescuer apparent on Top
1. A workplace example - Persecutor on top

The 'Helicopter Mom' was avoided as a busybody Persecutor, but secretly she is a Rescuer helping a struggling new employee so she will not get fired, and secretly a Victim too because of her worry about the failing new employee. Even worse, if that office does not meet production requirements under her watch, she could get fired. But no one forgave her in those roles because her Rescuer and Victim roles were submerged and underwater.

\section{A home example - Persecutor on top}

A father $(P-)$ could be heard yelling at a child who stayed out too late - with the mother quickly coming in with the Rescue $(\mathrm{R}+)$ of the crying child $\left(\mathrm{V}_{+}\right)$. But the mother may also be a hidden Persecutor ( $\left.\mathrm{P}_{-}\right)$by making the Dad look bad and splitting him off from the family, and supporting the child's (V-) misbehaviour

But the father, with $\mathrm{OK}$ assertion $(\mathrm{P}+)$ could need to make his point strongly because he has recently heard of dangers in the neighbourhood. So he is then a hidden, unsuspected OK Rescuer $(\mathrm{R}+)$ and an unappreciated and misunderstood Victim (V-) of the family which is falsely accusing him of heavy tactics. The Child may actually be a rebellious troublemaker (V-) playing the three-handed game with the parents of Let's You and Him Fight.

\section{A family example - Victim on top}

This could be a classic game of the child being the identified 'patient' (V-) in a dysfunctional family. But secretly the child functions as an underwater hidden Rescuer $(\mathrm{R}+)$ in his/her role as a lightning rod, sacrificing themselves to siphon off the dysfunctional anger in the family, and thereby keeping the family together and not getting mad enough at each other to split up.

As a hidden underwater Persecutor $(\mathrm{P}+)$ but seen as a $(P-)$, the child will keep escalating the game each time the family therapy sessions begin to change, because protecting the family integrity was the number one interest in this martyr child $\left(V_{+}\right)$.

As the identified client all four discounts of person roles were applied - the Child was treated as an XXXX of attributions, while the family portrayed themselves as all $\sqrt{ } \sqrt{ } \sqrt{ }$ s.

\section{A classic alcoholic family example - Rescuer on top}

We can look at the hidden roles of the codependent Rescuer in the home. She is the classic codependent covering up for her alcoholic husband ( $\mathrm{P}-$ ), she buys his alcohol, phones his workplace to make his excuses, puts on a brave face at her bridge party, tells her children Daddy is OK. But secretly she is a Persecutor ( $\left.\mathrm{P}_{-}\right)$keeping him dependent on her Rescuing so he cannot figure it out for himself by going 
to Alcoholics Anonymous. Secretly she is a Victim (V-) by staying trapped so she cannot create a life for herself, and a (R-) to herself by being in denial and lying to herself.

\section{In a sports example - Rescuer on top}

A famous athlete gets a contract for millions of dollars and becomes a lavish spender for all his friends and entourage $(R+)$ but secretly he is depriving his family of his presence and riches ( $\mathrm{P}-$ ) and eventually he becomes almost penniless and loses his family respect $(\mathrm{V}-)$, but with kindness his friends, family and church comes to his side to help him $(\mathrm{R}+)$.

\section{Instincts}

In summary, we have been planning a way to intelligently and compassionately look at the many different sides of every issue. In the process we are working against other instincts in negative memories, experiences and emotions that in certain circumstances can bring on an adrenalin fight state. In this state the primitive mind is intent on dispensing with the attacker, with no interest in understanding oneself or understanding the enemy - unless it is to find a weakness to exploit. This adrenalin can surface in a second-degree game and comes out in arguments where the goal is to win at all costs instead of exchanging information fairly for mutual winning. The lesson here of the compassion triangle is to wisely know that there are three different sides of every issue, instinctively derived, with variations to always consider. This can lead to a goal that with practice can lead to an automatic use of the extended compassion triangles, called the wisdom triangles (Karpman, 2014).

Stephen B. Karpman, M.D. is a Teaching and Supervising Transactional Analyst and was twice vice president of the ITAA serving on the Board of Trustees for 11 years. Dr. Karpman teaches widely across the United States and abroad. Academically, he is an Assistant Clinical Professor of Psychiatry at UCSF in San Francisco, where he also has his private practice. His articles, many out of print, are available free on his web site at www.KarpmanDramaTriangle.com. All comments to this article are invited by e-mail at egostates@aol.com or on the web site.

\section{References}

Applebaum, S. (1994). Essay on man and other poems. New York: Dover publications, Inc.

Berne, E. (1961). Transactional Analysis in Psychotherapy. New York: Grove Press.
Berne, Eric (1964a) Trading Stamps Transactional Analysis Bulletin 3127.

Berne, E. (1964b). Games People Play: The Psychology of Human Relationships. New York: Grove Press.

Dusay, J. (1972). Egograms and the 'Constancy Hypothesis.' Transactional Analysis Journal, 2(3), 37-41.

Grossart, A.B. (2012). The Complete Points of Sir John Davies. London: Forgotten Books.

Kahler, Taibi (1975) Drivers: The Key to the Process of Scripts. Transactional Analysis Journal 5:3 280-284

Kahler, T. (2008). The Process Therapy Model: The Six Personality Types with Adaptations. Little Rock, AK: Taibi Kahler Associates.

Karpman, S (1968) Fairy tales and script drama analysis. Transactional Analysis Bulletin 7, 39-43.

Karpman, S (1985). Make your wildest dream come true. Bulletin of The Eric Berne Seminar, 5 (2) 18-23.

Karpman, S. (2009). Sex games people play: Intimacy blocks, games, and scripts. Transactional Analysis Journal, 39, 103-116.

Karpman, S. (2010). Intimacy Analysis today: The intimacy scale and the personality pinwheel. Transactional Analysis Journal, 40 (3-4) $224-242$.

Karpman, S. (2012). Listening, Learning, and Accountability: Three Rules of Openness, Three Rules of Accountability, and the Adult Scales, Listening Scales, and Listener's Loops. Transactional Analysis Journal, 42 (1) 71 $-86)$.

Karpman, S (2014). A Game Free Life., San Francisco: Drama triangle publications.

Karpman, S. (2019). Script Drama Analysis II. International Journal of Transactional Analysis Research \& Practice 10 (1), 21-39

Mellor. K., \& Schiff, E. (1975a). Discounting. Transactional Analysis Journal (5) 295-30.

Mellor. K., \& Schiff, E. (1975b). Redefining. Transactional Analysis Journal (5) 303-311.

Schiff, A. W., \& Schiff, J. L. (1971). Passivity. Transactional Analysis Journal, 1(1), 71-78.

Steiner, Claude (1966) Scripts People Live, New York: Grove Press 